\title{
Reply to 'Comment on "Evidence for a large strike-slip component during the 1960 Chilean earthquake" by H. Kanamori, L. Rivera and S. Lambotte' by J. C. Savage
}

\author{
Hiroo Kanamori, ${ }^{1}$ Luis Rivera ${ }^{\circledR 2}$ and Sophie Lambotte ${ }^{2}$ \\ ${ }^{1}$ Seismological Laboratory, California Institute of Technology, Pasadena, CA 91125,USA.E-mail: hiroo@gps.caltech.edu \\ ${ }^{2}$ Université de Strasbourg, CNRS, ITES UMR 7063, F-67084 Strasbourg, France
}

Accepted 2021 September 7in original form 2021 August 9

Key words: Geomechanics; Earthquake dynamics; Earthquake source observations; Dynamics and mechanics of faulting; Subduction zone processes.

\section{INTRODUCTION}

We thank Dr Jim Savage for his interest in, and comment on, our paper (Kanamori et al. 2019, hereafter referred to as KRL19), where we showed that the commonly believed thrust-fault mechanism of the 1960 Chilean earthquake $\left(M_{\mathrm{w}}=9.5\right)$ is not compatible with teleseismic data (e.g. strain seismograms at Isabella, California, and Ogdensburg, New Jersey, and long-period seismograms at Pasadena, California and Berkely, California) and suggested that dextral-slip component comparable in amount to the dip-slip component is required. We did not test our model against the shear strain data in Chile published in Plafker \& Savage (1970). Savage (2021, hereafter referred to as S21) investigated whether the large dextral slip is compatible with the observed shear strain data. He concluded that the observed shear strain was very small, and provides no obvious evidence for large dextral component. However, he also stated that the absence of shear strain is not conclusive evidence of the absence of dextral slip. In fact, using a 2-D model, he showed in his fig. 9 that models with strike-slip moment comparable to the thrust moment can fit the observed uplift and strain data well. However, he noted that these models require remarkable balancing of contributions from the shallower (depths $<\sim 70 \mathrm{~km}$ ) and deeper strike-slip components. Savage thinks that such near-perfect cancelling is unlikely. Also, the distribution of the dextral slip shown in fig. 9 may appear somewhat unrealistic because it is very different from that of dip slip.

Savage's comment includes insightful suggestions on how the dextral-slip distribution affects the shear strain field, but does not include specific criticisms on our analysis of seismic data. Since it is more like a stand-alone paper elaborating on his earlier comment (Jim Savage, written communication to HK, 2010) on the geodetic data, here we extend Savage's analysis to further explore slip models compatible with geodetic, tsunami and seismic observations.

\section{ACCEPTABLE DEXTRAL-SLIP MODELS}

As Savage (2021) suggested, the key issue is to find acceptable dextral-slip models that explain the observed shear strains $\gamma_{2}$ that are nearly zero after the contribution from the dip-slip component is removed (figs $2 \mathrm{c}$ and $3 \mathrm{c}$ of S21). Savage also demonstrated that the problem can be essentially decoupled to two parts: 'dip-slip, uplift, $\gamma_{1}$ ' problem and 'dextral-slip, $\gamma_{2}$ ' problem. Although this decoupling is not perfect near the edge of a slip strip as shown by fig. 2c of S21, the effect of dip slip on $\gamma_{2}$ is generally small. Thus, to focus on the key issue, we simplify the problem to find dextral-slip models with a given seismic moment $M_{0}$ that yield $\gamma_{2} \approx 0$ at all the sites within the uncertainties given by the red bars on fig. 3c of S21.

We use exactly the same model geometry (Fig. A1, length $=1000 \mathrm{~km}$, down-dip width $=300 \mathrm{~km}$, strike $=\mathrm{N} 10^{\circ} \mathrm{E}$, $\operatorname{dip}=20^{\circ}$, divided into 12 along-strike strips; figs 1 and 2 of S21) and symbols used by S21. We write the $\gamma_{2}$ at the $j$ th location by

$\gamma_{2 j}=\sum_{i=1}^{12} b_{i} \Lambda_{i j}^{2}, \quad j=1,2, \ldots, 8$,

where $\Lambda_{i j}^{2}$ denote the values of $\gamma_{2}$ at the $j$ th location calculated for a unit dextral slip on the $i$ th strip, and $b_{i}$ is the amount of dextral slip on the $i$ th strip. We use the Okada's (1985) code for computation of $\Lambda_{i j}^{2}$.

Referring to Savage's (2021) preferred dip-slip model (fig. 3a of S21: average slip $=6.92 \mathrm{~m}, M_{0}=8.3 \times 10^{22} \mathrm{Nm}$, and $M_{\mathrm{w}}=9.2$ ), we first consider two reference models: (1) Model_S_1: the best-fit dextral-slip model $\left(b_{i}, i=1,2, \ldots, 12\right)$ that yields $\gamma_{2 j}=0$ for all $j$. This can be determined with the non-negative least-squares method (NNLS; Lawson \& Hanson 1974); (2) Model_S_2: a dextral-slip model with the same distribution as that of the Savage's best-fit thrust model given by fig. 3a of S21. The models and the slip distributions are given in Table 1 and Figs 1(a) and (b). Model_S_1 is similar to the one shown in a preliminary version of S21 (also KRLm140 of fig. 9b of S21) and is perfectly acceptable with RMS $\equiv \sqrt{\sum_{j=1}^{8}\left(\gamma_{2 j}-\gamma_{2 j}^{\text {target }}\right)^{2} / 8}=0.18 \mu$-strain, where $\gamma_{2 j}^{\text {target }}$ are the target values of $\gamma_{2 j}, 0$ in our case (Figs 1a and b). However, this model would appear tectonically unrealistic because its distribution is very different from that of the dip-slip model (fig. 3a of S21). Nevertheless, it is useful because it clearly illustrates a type of dextral-slip distribution that yields negligibly small $\gamma_{2}$ at all 

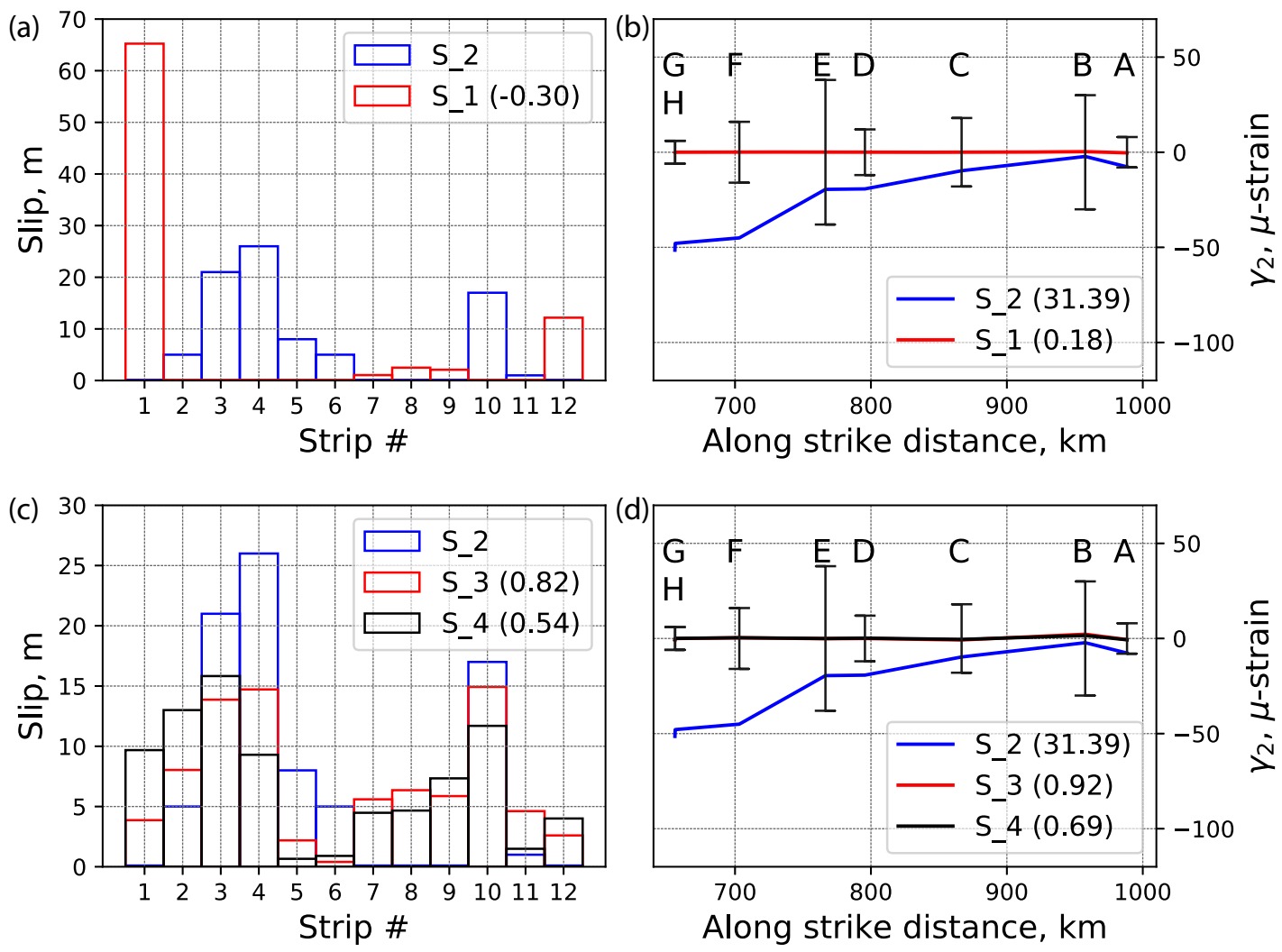

Figure 1. (a). Slip models Model_S_1 (red) and Model_S_2 (blue). (b). $\gamma_{2}$ for Model_S_1 (red) and Model_S_2 (blue) at sites A, B, C, D, E, F, G and H (locations are shown in fig. 1 of S21). The vertical bars indicate the error bars taken from S21. RMS is given in the parentheses. (c) Slip models Model_S_2 (blue), Model_S_3 (red) and Model_S_4 (black). The correlation coefficient, Cr, is given in parentheses. (d). Same as (b), for Model_S_2, Model_S_3 and Model_S_4.

the observation sites. It places almost the entire dextral slip in the strip furthest from the sites where $\gamma_{2} \mathrm{~s}$ were measured. In contrast, Model_S_2 is tectonically more reasonable but the $\gamma_{2}$ misfits are large (Figs 1a and b).

We explore a range of acceptable models starting from Model_S_2. Although the least-squares approach is useful to determine the best-fit model, it is not necessarily the most suitable for exploring a population of acceptable models. Here we use a Monte Carlo approach similar to that used by Press (1968) to find acceptable sets of Earth's shear wave speed distribution that are compatible with the normal-mode and surface wave data.

First, we give a shape of slip distribution, $b_{i}(i=1,2, \ldots, 12)$, of a test model and a range of slip from $b_{i_{-} \min }$ to $b_{i_{-} \max }$ on each strip. We compute the slip by

$b_{i}=r\left(b_{i, \max }-b_{i, \min }\right)+b_{i, \min }$,

where $r$ is an independent random number between 0 and 1 for each realization and is given to each strip. The slip distribution is normalized so that the average slip is always $6.92 \mathrm{~m}$ corresponding to the moment of Model_S-2. Then, we compute $\gamma_{2 j}$ by eq. (1), repeat it $N$ times while varying $r$, and compute the RMS. Here $N$ is typically $10^{8}$. We choose Model_S_2 as a model to guide the Monte Carlo search. We set the range $b_{i_{-} \max }$ and $b_{i_{-} \min }$ by adding $10 \mathrm{~m}$ to, and subtracting $5 \mathrm{~m}$ from, $b_{i}$ of Model_S_2, and use them in eq. (2). To maintain the positivity, we set $b_{i_{-} \min }=0$, if $b_{i_{-} \min }<0$. The resulting range is given in Table 1. Then, we perform the search described above and take the average of the 10 best slip models with the least RMS to obtain Model_S_3 (Table 1, Figs 1c and d). Although the RMS $=0.92 \mu$-strain for this model is considerably larger than that of Model_S_1, the misfit is small, almost indistinguishable from that of Model_S_1 as shown in Fig. 1(b). Thus, we consider Model_S_3 acceptable. The correlation coefficient, Cr, between Model_S_3 and Model_S_2 is 0.82 . This means that the acceptable dextral-slip distribution is not very different from that of the dip-slip distribution.

We can iterate this procedure using Model_S_3 as a guide, and can find a model with even smaller RMS (RMS $=0.69 \mu$-strain), but with a smaller $\mathrm{Cr}(\mathrm{Cr}=0.54)$. This model, Model_S_4, is given in Table 1 and Figs 1(c) and (d).

\section{COMPARISON WITH THE INVERSION RESULTS OF HO ET AL. (2019)}

Ho et al. (2019) performed slip inversion of the 1960 Chilean earthquake using the uplift data from Plafker \& Savage (1970) and tsunami data. Fig. A1 shows the fault geometry used by Ho et al. (2019). They obtained fault slip models with rake $=90^{\circ}, 110^{\circ}$ and $140^{\circ}$, which can explain the uplift and tsunami data. Since they did not include the shear strain data published by Plafker Savage (1970), here we compare the strains $\gamma_{1}$ and $\gamma_{2}$ computed for Ho et al.'s (2019) models with the data. Fig. 2 shows the comparison. It is interesting that the pure thrust model $\left(\right.$ rake $=90^{\circ}$ ) can produce non-zero (up to $20+\mu$-strain) $\gamma_{2}$ probably due to the edge effect mentioned earlier; it also explains well the spatial distribution of $\gamma_{2}$. Thus, at face value, the pure thrust model is a perfectly acceptable model. The model with rake $=110^{\circ}$ is equally good. The fit of $\gamma_{2}$ deteriorates for the model with rake $=140^{\circ}$. However, even for this model the maximum misfit of $\gamma_{2}$ is relatively small, about $60 \mu$ strain. Since the locations of A, B, C, ..., E are close to the eastern 
Ho et al., rake $=90^{\circ}$
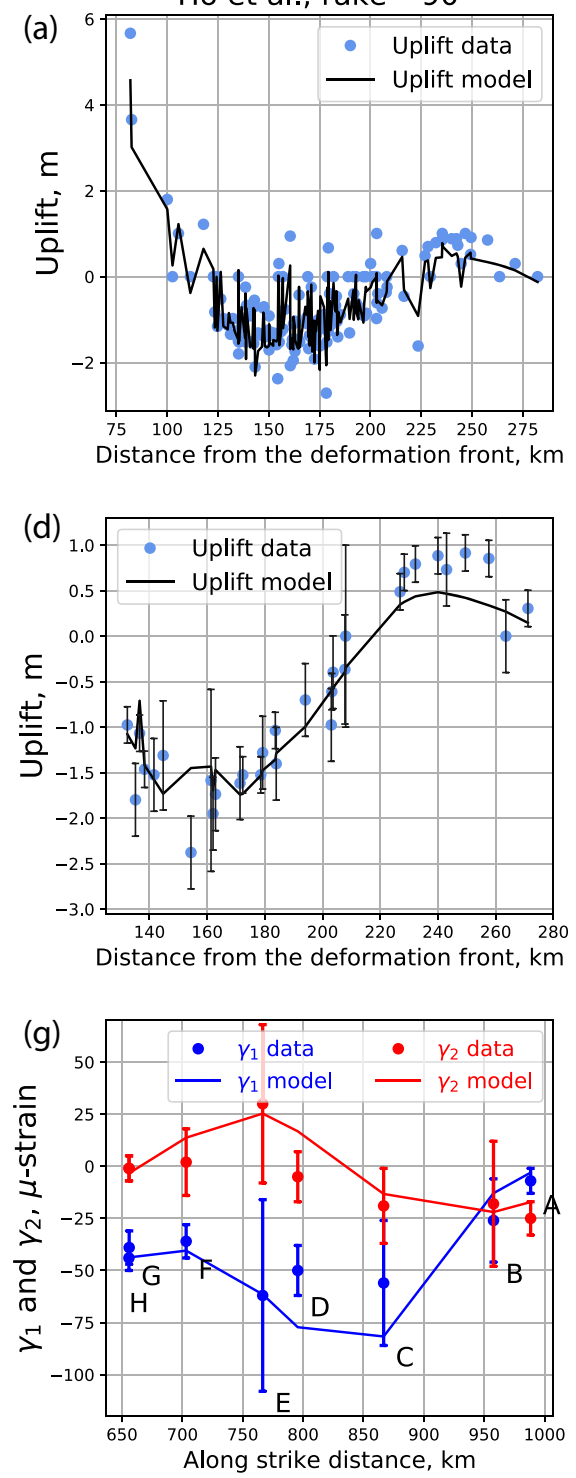

Ho et al., rake $=110^{\circ}$
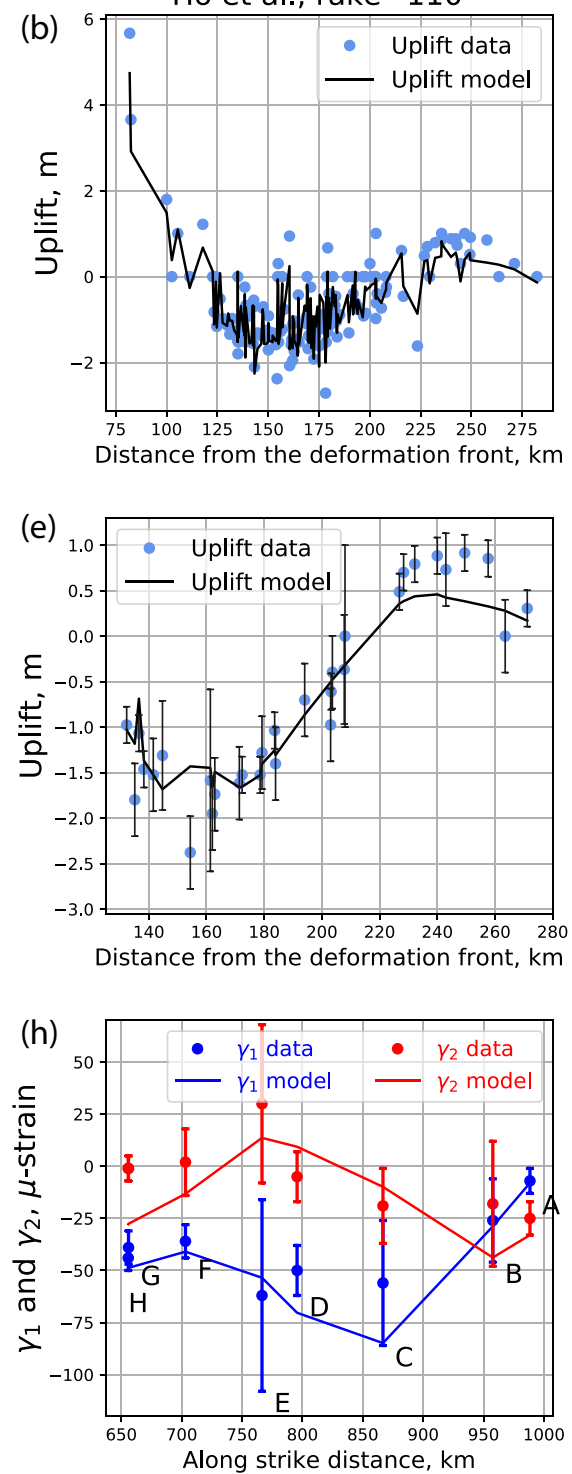

Ho et al., rake $=140^{\circ}$
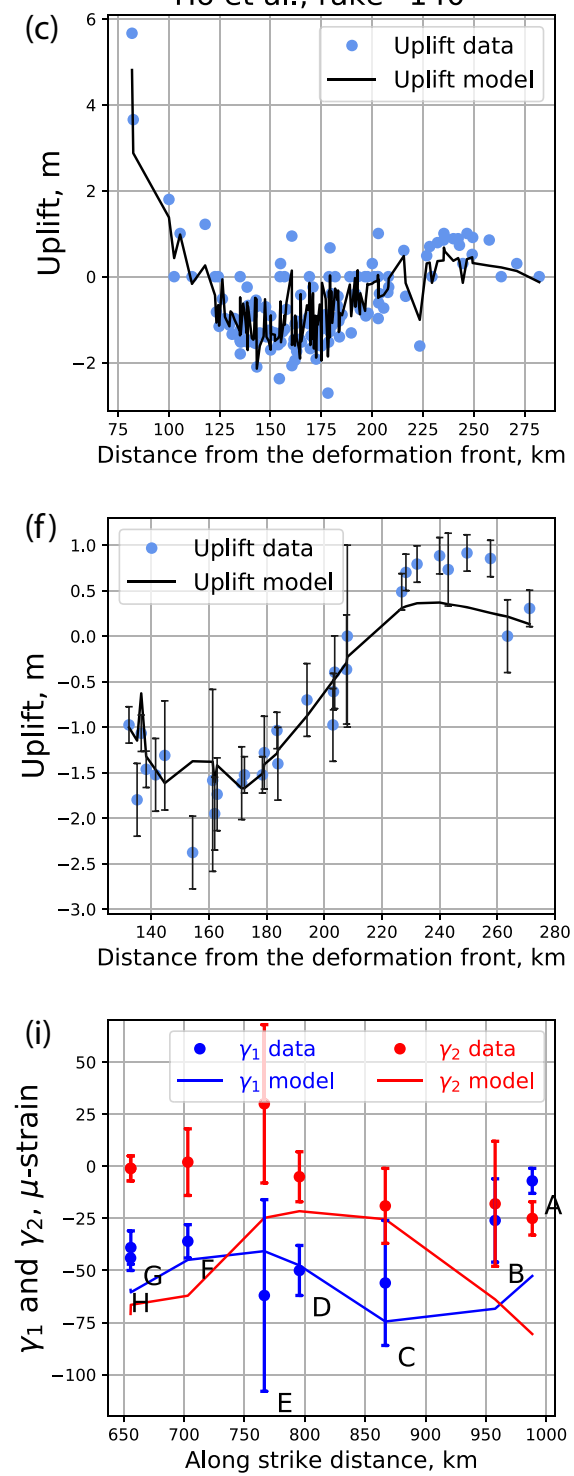

Figure 2. Uplift, strain $\gamma_{1}$ and strain $\gamma_{2}$ for the slip models of Ho et al. (2019). Left: rake $=90^{\circ}$; middle: rake $=110^{\circ}$; right: rake $=140^{\circ}$. Panels (a)-(c) show the complete set of uplift data given in Plafker \& Savage (1970). Panels (d)-(f) show the uplift along the EW trending line shown in Plafker \& Savage (1970) for locations from \#24 to \#55. Panels (g)-(i) show the strains $\gamma_{1}$ and $\gamma_{2}$ at locations A, B, C, D, E, F, G and H.
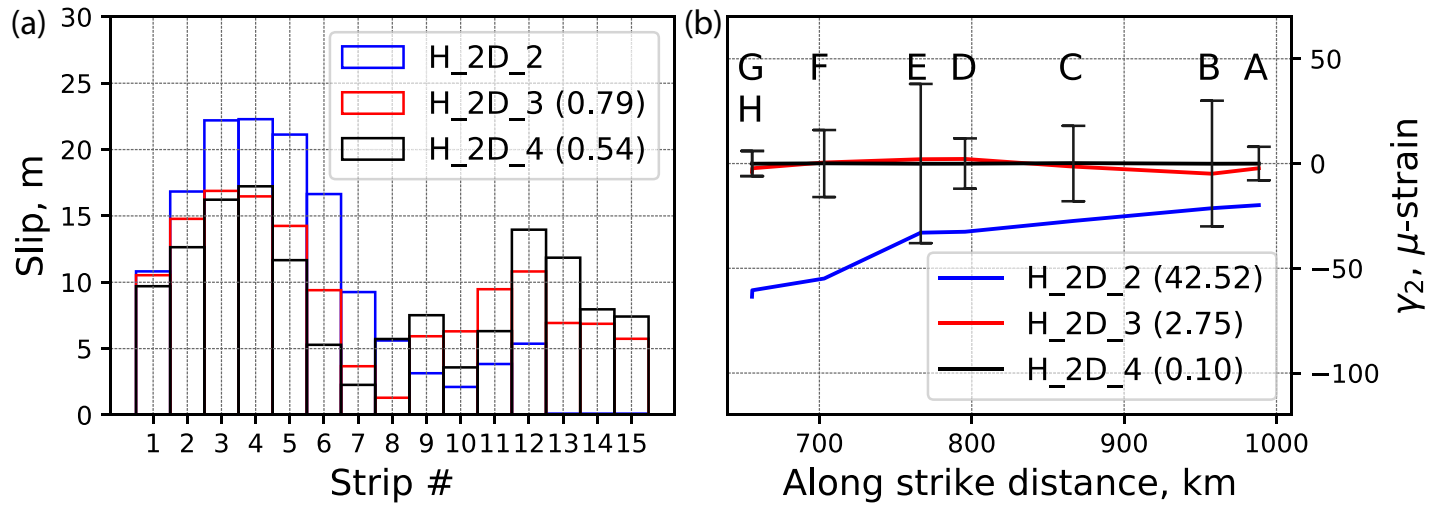

Figure 3. (a) Dextral-slip distributions for Model_H_2D_2 (blue), Model_H_2D_3 (red) and Model_H_2D_4 (black). The correlation coefficient, Cr, is given in parentheses. (b) $\gamma_{2}$ for the three models. RMS is given in the parentheses. 


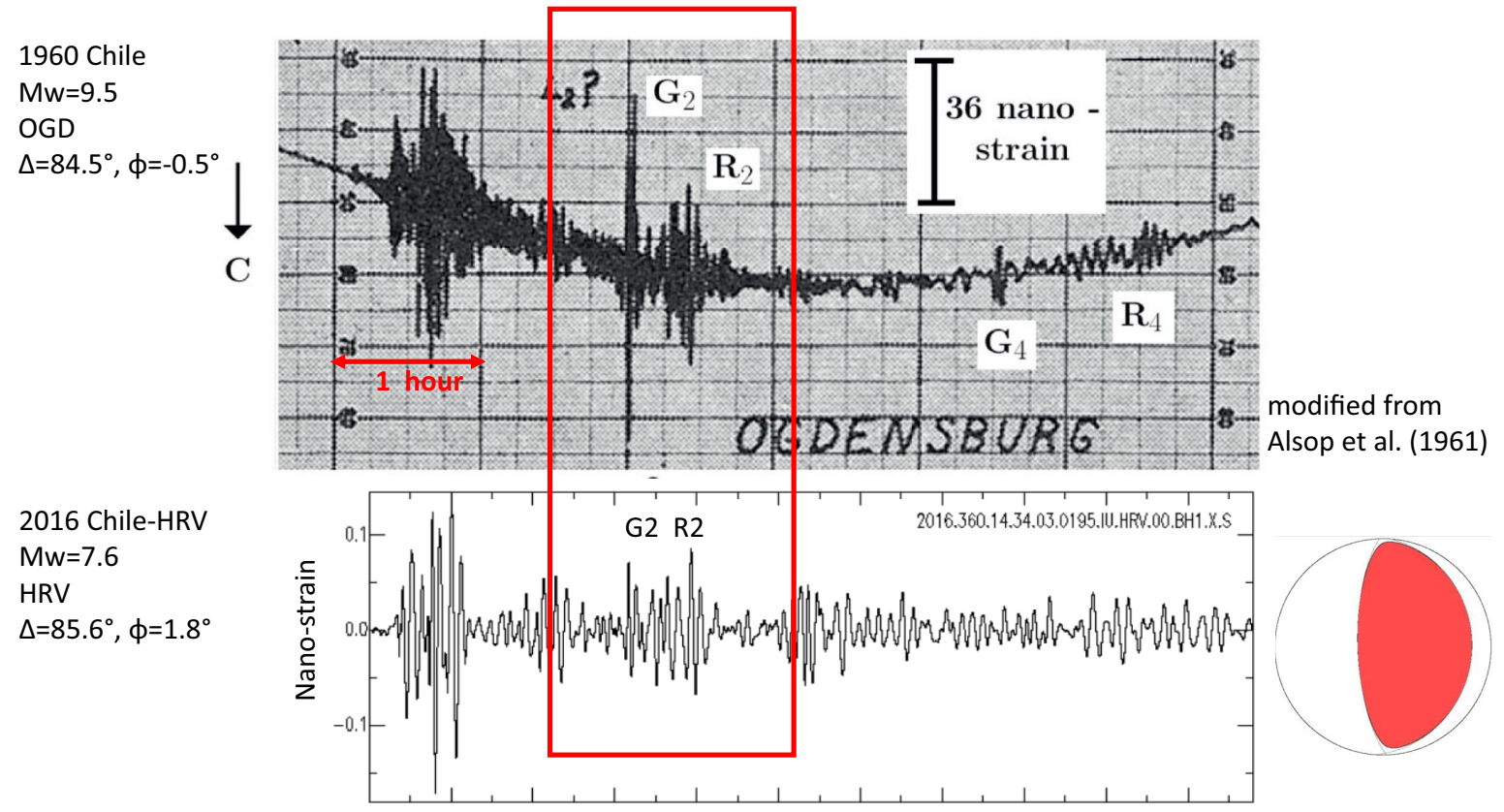

Figure 4. Top: strain seismogram of the 1960 Chile earthquake recorded at Ogdensburg, New Jersey (modified from Alsop et al. 1961). Bottom: simulated strain seismogram of the 2016 Chile earthquake computed from the horizontal seismograms recorded at HRV. Long-period surface waves $\mathrm{G}_{2}$ and $\mathrm{R}_{2}$ are shown in the red box. The mechanism of the 2016 event is shown at the bottom right corner.

Table 1. Slip models and test range. Unit of slip $=\mathrm{m}$, unit of RMS $=\mu$-strain. $\mathrm{Cr}$ is the correlation coefficient between Model_S_2 and Model_S_3, and between Model_S_2 and Model_S_4.

\begin{tabular}{lccccc}
\hline Strip \# & Model_S_1 & Model_S_2 & Range & Model_S_3 & Model_S_4 \\
\hline 1 & 65.24 & 0 & $0-10$ & 4.1 & 9.7 \\
2 & 0 & 5 & $0-15$ & 8.0 & 13.0 \\
3 & 0 & 21 & $16-31$ & 13.6 & 15.8 \\
4 & 0 & 26 & $21-36$ & 14.7 & 9.3 \\
5 & 0 & 8 & $3-18$ & 2.4 & 0.7 \\
6 & 0 & 5 & $0-15$ & 0.30 & 0.9 \\
7 & 1.05 & 0 & $0-10$ & 5.7 & 4.5 \\
8 & 2.49 & 0 & $0-10$ & 6.3 & 4.7 \\
9 & 2.09 & 0 & $0-10$ & 5.7 & 7.3 \\
10 & 0 & 17 & $12-27$ & 16.7 & 11.7 \\
11 & 0 & 0.0 & $0-11$ & 2.2 & 1.5 \\
12 & 1.0 & 0 & 3.3 & 4.0 \\
& RMS $=0.18$ & $\mathrm{RMS}=32$ & & $\mathrm{RMS}=0.92$ & $\mathrm{RMS}=0.69$ \\
& & $\mathrm{Cr}=1.0$ & & $\mathrm{Cr}=0.81$ & $\mathrm{Cr}=0.54$ \\
\hline
\end{tabular}

border of the Ho et al.'s fault (Fig. A1), the cancellation effect is small in this case; the remoteness of the high slip zone leads to the observed low $\gamma_{2}$.

In the following we briefly discuss how we can further reduce this misfit to an acceptable level. We do not attempt to perform inversion to obtain another model. Such an attempt is beyond the scope of this short reply, especially given the very underdetermined and underconstrained situation because of the limited spatial coverage of the data.

Since Ho et al.'s model has 436 slip patches, the Monte Carlo approach is not practical or effective for such a large number of unknowns. Hence, we simplify the problem by reducing the Ho et al.'s slip model to a simple 2-D model like the Savage's. We also extend the fault plane downdip by adding 3 along-strike strips (total of 15 strips, each $20 \mathrm{~km}$ wide) so that we have a total fault width of $300 \mathrm{~km}$, the same as Savage's (Fig. A1). Then, we take the average slip for each strip of Ho et al.'s model and assign it to the 2-D model. The 2-D model has the same geometry (dip and strike) and the moment as the Ho et al.'s model. The resulting 2$\mathrm{D}$ strip model for rake $=140^{\circ}$ case (Model_H_2D_2) is shown in Table 2 and Fig. 3(a) (blue). For this model, RMS $=42.51 \mu$-strain which is comparable to that for Model_S_2. Then, we apply the same Monte Carlo search as that used for the Savage model. The resulting model (Model_H_2D_3) is shown in Fig. 3(a) (red). For this model $\mathrm{RMS}=2.75 \mu$-strain and $\mathrm{Cr}=0.79$. Then, using Model_H_2D_3 as a starting model, we iterate the search and obtain Model_H_2D_4 [Table 2 and Fig. 3a (black)] for which RMS $=0.10 \mu$-strain and $\mathrm{Cr}=0.54$. RMS is very small and the $\gamma_{2}$ misfit is almost 0 . Thus, we can show that with a relatively minor modification of the $2 \mathrm{D}$ version of Ho et al.'s model with rake $=140^{\circ}$ we can match the $\gamma_{2}$ shear strain data without difficulty. Fig. 3(a) clearly shows the nature of modification: reduce the dextral slip for strips in the updip portion of the fault plane (especially strips \#5, 6 and 7) and increase the slip for strips in the downdip portion (strips \#12, 13, 14 and 
Table 2. Slip models for the fault geometry of Ho et al. (2019), unit of slip $=\mathrm{m}$, unit of RMS $=\mu$-strain.

\begin{tabular}{lccc}
\hline Strip \# & Model_H_2D_2 & Model_H_2D_3 & Model_H_2D_4 \\
\hline 1 & 10.82 & 10.53 & 9.70 \\
2 & 16.84 & 14.78 & 12.64 \\
3 & 22.201 & 16.89 & 16.22 \\
4 & 22.290 & 16.47 & 17.23 \\
5 & 21.13 & 14.25 & 11.67 \\
6 & 16.65 & 9.40 & 5.29 \\
7 & 9.26 & 3.67 & 2.27 \\
8 & 5.61 & 1.30 & 5.72 \\
9 & 3.14 & 5.93 & 7.52 \\
10 & 2.11 & 6.30 & 3.58 \\
11 & 3.84 & 9.48 & 6.32 \\
12 & 5.37 & 10.81 & 13.96 \\
13 & 0. & 6.93 & 11.85 \\
14 & 0. & 6.87 & 7.96 \\
15 & 0. & 5.74 & 7.42 \\
& RMS $=42.51$ & RMS $=2.75$ & $\mathrm{RMS}=0.10$ \\
& & $\mathrm{Cr}=0.79$ & $\mathrm{Cr}=0.54$ \\
\hline
\end{tabular}

15). This is exactly the trend suggested by Savage (2021) from his fig. 2(d).

This analysis could be extended to the original 3-D model of Ho et al. (2019), but since the number of unknowns increases from 15 to 436 , the problem becomes extremely underdetermined and nonunique. Since all the strain measurements are in the northeastern end of the rupture zone (Fig. A1), we can easily reduce $\gamma_{2}$ by placing the dextral slip in the southern half of the fault plane, especially southeastern end of the fault plane (Fig. A1). In this case, we do not need to invoke the balancing effect of shallow and deep dextral slips for reducing the shear strain. The final choice should be made depending on whether the resulting slip distribution is tectonically realistic or not.

Another interesting point here is that Fig. 2 shows that Ho et al.'s models tend to slightly underpredict the uplift along the line from 240 to $270 \mathrm{~km}$ from the deformation front (Figs 2d-f). This misfit can be reduced if we place about $10 \mathrm{~m}$ dip slip in the extended strips $\# 13$ to \#15. This amount is comparable to that of the dextral slips of our Model_H_2D_3 and Model_H_2D_4. Such deep slips have been suggested by Linde \& Silver (1989) and Barrientos \& Ward (1990). Savage (2021) notes that such deep coseismic slip may be unrealistic because it has not been observed for other megathrust events. However, recent observations have demonstrated that earthquakes are all different in substantial ways.

\section{FURTHER SEISMOLOGICAL EVIDENCE}

The most important evidence for the dextral component documented in KRL19 is from long-period strain records at Isabella and Ogdensburg, and long-period seismograms at Pasadena and Berkeley. Since the availability of historical data is limited, it is desirable to find more relevant seismic data. In this respect, the $M_{\mathrm{w}} 7.6$ earthquake that occurred on 2016 December 26 near the southern end of the 1960 Chilean earthquake rupture zone is important. The mechanism of this event is almost pure thrust (Fig. 4). Thus, if the 1960 event was a pure thrust, the 2016 event should produce similar seismograms to those of the 1960 event. The Ogdensburg strain record (Alsop et al. 1961; fig. 7 in KRL19) is of particular interest. Although we do not have a strain seismogram at Ogdensburg for the 2016 event, we can simulate it from the seismograms recorded at nearby stations. As
Benioff (1935) showed, an extensional strain seismogram can be approximately simulated by

$\frac{\partial u_{l}}{\partial l}=-\left(\frac{\cos (\psi)}{C_{0}}\right) \frac{\partial u_{l}}{\partial t}$

where $l$ is the distance measured in the strain rod, $u_{l}$ is the displacement in the direction of the strain rod, $t$ is time, $\frac{\partial u_{l}}{\partial t}$ is the ground motion velocity, $\psi$ is the azimuth of the strain rod measured from the great circle path and $C_{0}$ is the phase velocity of the wave being looked at. Strictly speaking, the phase velocity is different between the transverse wave (e.g. Love wave) and the longitudinal wave (e.g. Rayleigh wave), but since the fundamental mode Love and Rayleigh waves have approximately the same phase velocity in the period range of our interest, we ignore the difference and use $C_{0}=5.5 \mathrm{~km} \mathrm{~s}^{-1}$. Long-period surface waves from the 2016 event were recorded at the station HRV. The epicentral distance and azimuth of $\operatorname{HRV}\left(\Delta=85.6^{\circ}\right.$ and $\left.\varphi=1.8^{\circ}\right)$ and Ogdensburg $\left(\Delta=84.5^{\circ}\right.$ and $\varphi=0.5^{\circ}$ ) are similar. Fig. 4 compares the simulated strain record for the 2016 event with the Ogdensburg strain record of the 1960 event. The simulated record is low-pass filtered at $0.005 \mathrm{~Hz}$. The amplitude ratio of $\mathrm{G}_{2} / \mathrm{R}_{2}$ is very different between the 1960 and 2016 events, providing evidence that the 1960 Chilean earthquake and the 2016 event have very different mechanisms. A similar comparison was made in KRL19, but we used synthetic seismograms for comparison (fig. 7 of KRL19). Although the longwavelength Earth's heterogeneity is included in the computation of the synthetics, possible short-wavelength structural heterogeneities could not be included. Thus, the use of actually recorded seismograms of the 2016 event for comparison is more robust and desirable.

\section{CONCLUSION}

As Savage (2021) shows, a simple pure thrust model can explain well the existing uplift and strain data. However, with the commonly practiced criterion for the match of long-period seismic amplitudes, such a model is not compatible with the strain data at Isabella and Ogdensburg, and seismic data at Pasadena and Berkeley documented in KRL19. We can show that significant amounts of dextral slip can be added to the dip-slip components of the models presented by S21 and Ho et al. (2019) without violating the local shear strain data. Because of the limited spatial coverage of the near-field data and the limited amounts of teleseismic data, we cannot determine a unique model, but we can find models that are compatible with all the existing uplift, local strain, tsunami and teleseismic data. The dip-slip part of the model can remain the same as those previously established by Plafker \& Savage (1970), Barrientos \& Ward (1990), Moreno et al. (2009) and Ho et al. (2019).

In this short reply, we did not consider possible dextral slips on the Liquiñe-Ofqui Fault Zone (LOFZ). It would be interesting to explore a range of plausible dextral-slip models for LOFZ, if we have further geophysical motivation to investigate slip partitioning at subduction zones (Kanamori \& Rivera 2018).

Data accessibility. All the data used are published in Plafker \& Savage (1970) and Savage (2021). The waveform data used were accessed from The Data Management System of the Incorporated Research Institutions for Seismology (http://www.iris.edu/hq/).

Conflict of Interest. We declare we have no conflict of interest. Funding. We have no specific funding for this Reply. 


\section{ACKNOWLEDGEMENTS}

We thank Jim Savage for sending us an early version of his manuscript, which allowed us to understand the nature of the strain data used for establishing the slip model of the 1960 Chilean earthquake. His comments are insightful and useful for finding a range of acceptable slip models. The Data Management System of the Incorporated Research Institutions for Seismology (http://www.iris.edu/hq/) was used to access the seismic data from the Global Seismic Network stations. We thank Editor Carl Tape for constructive comments.

\section{REFERENCES}

Alsop, L.E., Sutton, G.H. \& Ewing, M., 1961. Free oscillations of the Earth observed on strain and pendulum seismographs, J. geophys. Res., 66(2), 631-641.

Barrientos, S.E. \& Ward, S.E., 1990. The 1960 Chile earthquake: inversion for slip distribution from surface deformation, Geophys. J. Int., 103, 589598.

Benioff, H., 1935. A linear strain seismograph, Bull. seism. Soc. Am., 25(4), 283-309.

Hayes, G.P., Wald, D.J. \& Johnson, R.L., 2012. Slab1.0: a three-dimensional model of global subduction zone geometries, J. geophys. Res., 117(B1), B01302, doi:10.1029/2011JB008524.

Ho, T.-C., Satake, K., Watada, S. \& Fujii, Y., 2019. Source estimate for the 1960 Chile earthquake from joint inversion of geodetic and transoceanic tsunami data, J. geophys. Res., 124, 2812-2828.

Kanamori, H. \& Rivera, L.A., 2018 Implication of the $1960 M_{\mathrm{w}}=9.5$ Valdivia, Chile, earthquake and the $M_{\mathrm{w}}=7.7$ Aysén slow earthquake for slip partitioning along the south Chile subduction zone, in $A G U$ Fall Meeting Abstracts, pp. T52B-07.

Kanamori, H., Rivera, L. \& Lambotte, S., 2019. Evidence for a large strikeslip component during the 1960 Chilean earthquake, Geophys. J. Int., 218 , $1-32$.

Lawson, C.L. \& Hanson, R.J., 1974, Solving Least Squares Problems, Prentice-Hall. p. $158 \mathrm{ff}$.

Linde, A.T. \& Silver, P.G., 1989. Elevation changes and the great 1960 Chilean earthquake: support for aseismic slip, Geophys. Res. Lett., 16, 1305-1308.
Moreno, M.S., Bolte, J., Klotz, J. \& Melnick, D., 2009. Impact of megathrust geometry on inversion of coseismic slip from geodetic data: application to the 1960 Chile earthquake, Geophys. Res. Lett., 36, L16310, doi:16310.11029/2008GL039276.

Okada, Y., 1985. Surface deformation due to shear and tensile faults in a half-space, Bull. seism. Soc. Am., 75, 1135-1154.

Plafker, G. \& Savage, J.C., 1970. Mechanism of the Chilean earthquakes of May 21 and 22, 1960, Bull. geol. Soc. Am., 81, 1001-1030.

Press, F., 1968. Earth models obtained by Monte Carlo inversion, J. geophys. Res., 73(16), 5223-5234.

Savage, J.C., 2021. Comment on 'Evidence for a large strike-slip component during the 1960 Chilean earthquake' by H. Kanamori, L. Rivera, and S. Lambotte, Geophys. J. Int., this issue.

\section{APPENDIX A:}

Since the fault models used by Savage (2021) and Ho et al. (2019) are slightly different, we show them schematically in Fig. A1, which displays the horizontal projections of the fault plane on a map together with the locations, A, B, C, . , H, where the strain measurements were made. The fault model used by Savage (red) is a $1000 \mathrm{~km} \times 300 \mathrm{~km}$ rectangular plane with a dip $=20^{\circ}$ and strike $=\mathrm{N} 10^{\circ} \mathrm{E}$. It is divided into 12 along-strike strips each $25 \mathrm{~km}$ wide. The southwestern corner is at $46.885^{\circ} \mathrm{S}$ and $76.420^{\circ} \mathrm{W}$. The model used by Ho et al. is not a simple plane. It is divided into 436 subfaults each having a different dip angle. Each subfault has an area of approximately $\left(0.248^{\circ}\right.$ latitude $) \times\left(0.248^{\circ}\right.$ longitude $)$ which varies considerably with latitude. Thus, the width of the fault is not uniform. It is $233.0 \mathrm{~km}$ on the southern side and $266.4 \mathrm{~km}$ on the northern side. The overall shape is defined by the Slab 1.0 plate boundary model (Hayes et al. 2012). For the purpose of comparison with the Savage model, we added three along-strike strips each $20 \mathrm{~km}$ wide. The areas occupied by grey '+'s and circles indicate the original fault plane of Ho et al. and the extended portion, respectively. The horizontal projection of the overall shape of the extended fault is shown in the figure (blue). We computed the coefficients $\Lambda_{i j}^{2}$ using the exact subfault geometry used by Ho et al. (2019). 


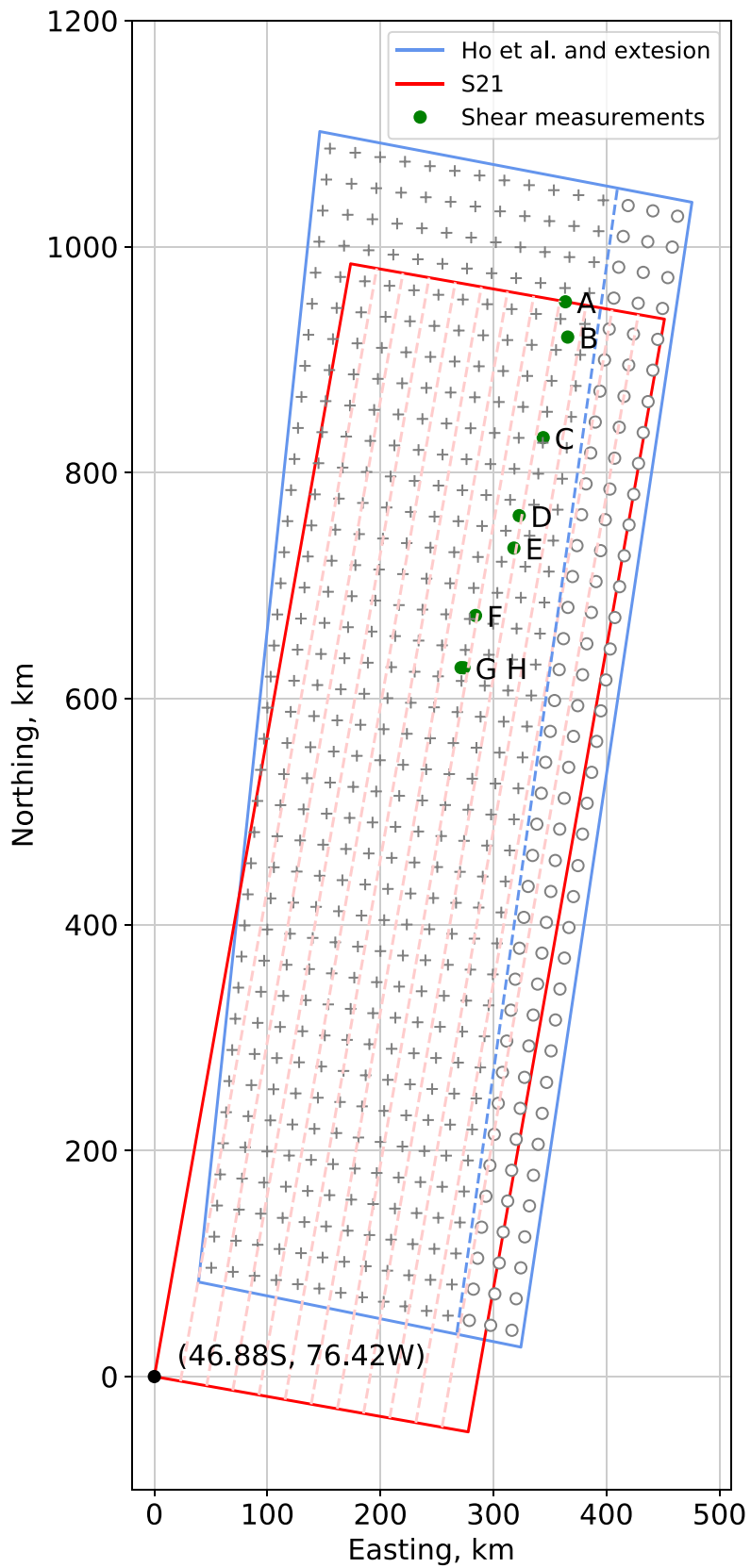

Figure A1. Horizontal projection of the fault models used by Savage (2021) and Ho et al. (2019). The fault model used by Savage (red) is a $1000 \mathrm{~km} \times$ $300 \mathrm{~km}$ rectangular plane with a dip $=20^{\circ}$ and strike $=\mathrm{N} 10^{\circ} \mathrm{E}$. It is divided to 12 along-strike strips each $25 \mathrm{~km}$ wide. The southwestern corner is located at $46.885^{\circ} \mathrm{S}$ and $76.420^{\circ} \mathrm{W}$. The model used by Ho et al. is not a simple plane. It is divided into 436 subfaults each having a different dip angle. Each subfault has an area of approximately $\left(0.248^{\circ}\right.$ latitude $) \times\left(0.248^{\circ}\right.$ longitude $)$ which varies considerably with latitude. Thus, the width of the fault is not uniform, $233.0 \mathrm{~km}$ on the southern side and $266.4 \mathrm{~km}$ on the northern side. For the purpose of comparison with the Savage model, three along-strike strips are added. The areas occupied by grey ' + 's and circles indicate the original fault plane of Ho et al. and the extended portion, respectively. The extended fault (blue) is divided to 15 along-strike strips, each about $20 \mathrm{~km}$ wide. $\mathrm{A}, \mathrm{B}, \mathrm{C}, \ldots, \mathrm{H}$ indicate the locations where the strain measurements were made. 